\title{
Analysis on Theories and Countermeasures for University to Achieve Integrated Document Management
}

\author{
Shumin Cui \\ Management of teaching and research base \\ Jilin Agricultural University \\ Changchun,,China \\ 729738677@qq.com \\ +8615604305161
}

\begin{abstract}
In the process of archival management and innovation, we must change the traditional mode of thinking, foster the innovation goals of user-centric and knowledge service system, adopt an integrated document management model, break the limitations of physical files, and take a direct management, processing and utilization on information.
\end{abstract}

Key word- university, integrated document management, countermeasure

\section{INTRODUCTION}

With the development and continuous optimization of information technology, the diversity of archive carrier, the innovation of content, and the efficiency of management instruments can be more prominent. The management of files and archives must be networked, diversified and complicated. One of the obvious characters of digital information resources and information networking is that the way and speed of the generation and dissemination of human knowledge have passed through a qualitative change. This change not only displays in the storage and capacity of archival information resources. Besides, the delivery and service mode of archival information resources have also undergone a very profound change.

\section{THE CURRENT SITUATION OF INTEGRATED DOCUMENT MANAGEMENT OF UNIVERSITY}

\section{A. Connotation information construction of University Archives}

To implement integrated document management is the objective need for the information construction of University Affairs. The rapid development of computer technology, network technology, and modern communication technology, has provided a strong technical support for the university's informationization construction and allowed the informationization of University Affairs, which is represented by office automation, archive informationization and other information management systems, to be rapidly spread and popularized and to be gradually stepped into the fast lane of rapid development. There are indications that after the first decade of the 21st century, the education management of university has entered into a new era of informationization, networking, and automation ${ }^{[1]}$. The era dominated by traditional paper documents has been quietly weakening. The parallel development of paper documents and electronic documents will become the mainstream for the future document management, which forces the university administrators and document management departments to adapt to the pace of informationization development, seize the opportunity, plan scientifically, accelerate the process of integrated document management from the aspect of management and technology, and escort the university's informationization construction.

\section{B. Constraints for the enforcement of university's integrated document management.}

There are mainly four obstacles or constraints for university to implementation integrated document management: The first one is institutional factors. The internal university's departments of documents, business, archives, have long been independent of each other. The closed operation system has resulted in failure of receipt of documents and archives and irregular archive and other phenomena's frequent occurrence, which largely destroyed the continuity and integrity of documents and files and also greatly affected the future examination and utilization ${ }^{[2]}$. All construction will be impossible without adequate funding. Both the investment of hardware and software of informationization construction and the technical training of relevant personnel need funding insurance. The last is cognition factor. Some university leaders are lack of adequate attention and awareness on the cultural heritage and historical significance of archives. There are also some personnel of the archive departments are lagging behind in management philosophy, accustomed to the traditional way, lack of advanced awareness, having a weak interest and inadequate conscious in the integrated document management of the information age.

\section{THE SOLUTION IDEAS TO ACHIEVE THE INTEGRATED DOCUMENT MANAGEMENT}

\section{A. Create archive management system of electronic document}

The standardized management of electronic information during the process of the current business development of various functional departments in university is the prerequisite for the formation of a true, complete, and effective digital archive after archiving electronic documents. The system-dependent of electronic documents determines that their management must be attached to the system environment. The integrity guarantee, readability verification, and the management and utilization separating from existing business systems after archiving is a complex exchange of information and a complex process format 
conversion which involves a number of IT knowledge and management studies, involves various criteria, norms and methods, and even involves process restructuring and process optimization of the business system of some school sectors. Therefore, the archive management system of electronic document should be established, the close integration between various departments should be promoted, the integrated specifications of archiving electronic documents should be formed ${ }^{[3]}$.

\section{B. Initiative and advanced intervention of archive sector}

Archivists should take initiative and advanced intervention during the process of archiving and management of electronic document and guide the front-end business to implement archive management. During the process of electronic document generation and archiving, if the archivists are not concerned with the electronic file type, the effective reading form of archiving content in the process of running current business system, the responsibility chain information of the process of the formation of electronic documents and so on, then the authenticity, completeness, effectiveness, and readability of electronic files they received cannot be ensured. Therefore, archivists should take an advanced intervention in the first place, then intervene initiatively, and implement the front-end operational guidance in the end. Thus, the favorable conditions for the realization of integrated document management will be created.

\section{Take a comprehensive grasp of the business process of document integration}

The document life cycle theory tells us that it is a complete life process for the document from its generation and formation to its final destruction or permanent preservation as archives. They are mutual related and mutual influenced. Therefore, putting the documents and archives into a unified management system is both conducive to exerting the systematic advantage of documents and archive information resource and in line with the requirement of the rapid development of modern management of archive (chamber).

\section{Make sure the functional structure of document integration system}

The function of information system of integrated document management includes: system maintenance, management of receipt, management of document issuance, archive management, document management and file management. These modules are interconnected and integrate and share internal information, which truly realizes the natural archive and integrated management from electronic documents to electronic archives.

( 1 ) Management of receipt: the function of management of receipt is mainly as follows: Handle and record the communications of superior and the same level in form of electronic document. Users can find relevant documents and operate quickly and efficiently based on the registration date of documents, the degree of urgency, the current transfer status, and other process information. It mainly includes: receipt registration, receipt transfer, document reminders, process monitoring, document publishing, etc.

(2 ) Management of document issuance: the function of management of document issuance is mainly to process and forward internally developed or external documents. After drafting the electronic document, the approval and modification of the presenter and countersigned department staff should be passed step by step. Finally, it should be submitted to the leadership to issue and form into a formal document, and then register the archive. It mainly includes: drafting of document issuance, circulation of document issuance (including modifications traces, red chromatography of document), document reminders, process monitoring, publishing and other major work ${ }^{[4]}$.

(3) Archive management: Currently, archiving of electronic documents mainly adopts two ways: The first is: Automatic archiving can be achieved from the Internet through the electronic document transmission system of the unit's internal LAN. The second is: While the filing sectors are transferring paper archives to archives, they should hand over the file storage medium, such as disks and optical disks to store electronic documents. This method is mainly used for the transfer of some important evidence or confidential electronic documents. The management after archiving should also be taken appropriate physical isolation methods and security measures. These archives cannot be stored on the network in order to prevent leaks.

(4) File management: According to the relevant standards of national file management, the transfer, receival, review, preservation, management, query, statistic, and provision of services and utilization of the files are implemented. Each unit can create corresponding file information resource library according to the types of file information or the source of files. It can also establish a rapid retrieval mechanism based on archiving date, archiving department or the entity classification of files to facilitate borrow and provide access to utilization ${ }^{[5]}$.

\section{CONCLUSION}

Universities should correctly handle the seamlessly link between office automation system and archive informationization system. Departments of business functions should enhance the awareness of archive management and establish archive management system of electronic documents. Archivists should actively participate in the practical construction of document integrity and implement front-end control. They should also participate in the whole process, guide positively, and supervise checks. In the management practice of office automation and archive informationization, the relationship between existing electronic documents and electronic archives will be closer. Integrate the two into a comprehensive management system as the front and rear link and the interacting subsystem. Organize and control the whole process of the entire document life cycle to meet the needs of the 
managementnformationization of modern university education and sustainable development.

\section{REFERENCES:}

[1] Chen Guorong. Study on Theory and Practice of Integrated Document Management of University [J]. China Science and Technology Information, 2009 (11) :36-38.

[2] Chen Guangling. Innovative Research of University Archives Management Based on Document Integration [J]. Lantai World, 2008(12):27-28.

[3] Ni Daoshan. The Chain Method and Integrity of Documents [J].Archives, 2005 (5) : 15-18.

[4] Song Qin. Analysis on the Development Stage and Models of China's Integrated Document [J]. Archives Science Study, 2003 (2) : 13-20.

[5] Ni Daoshan. Law and document archives chain integration [J].File, 2005 (5) :15-18. 